\title{
Applying Experimental Philosophy to Investigate Economic Concepts : Choice, Preference, and Nudge
}

\section{Nagatsu, Michiru}

$T \& T$ Clark

2019

Nagatsu, M 2019 , Applying Experimental Philosophy to Investigate Economic Concepts :

Choice, Preference, and Nudge . in D A Wilkenfeld \& R Samuels (eds), Advances in Experimental Philosophy of Science. Advances in Experimental Philosophy, T \& T Clark, London , pp. 147-171 . https://doi.org/10.5040/9781350068896.0012

http://hdl.handle.net/10138/306054

https://doi.org/10.5040/9781350068896.0012

draft

Downloaded from Helda, University of Helsinki institutional repository.

This is an electronic reprint of the original article.

This reprint may differ from the original in pagination and typographic detail.

Please cite the original version. 


\title{
Applying Experimental Philosophy to Investigate Economic Concepts: Choice, Preference, and Nudge
}

\author{
Michiru Nagatsu
}

\section{Introduction}

Philosophers of science discuss not only general epistemological and metaphysical questions about explanation, causation, evidence, and the like, but also conceptual questions concerning the nature of scientific concepts such as genes, culture, and rationality. One might expect less disagreements in the latter debates, since the philosophical analyses are presumably based on the same "best scientific theories" available at the moment. The disagreements over the exact nature of these scientific concepts, however, seem sometimes more fundamental than those over, for example, what constitute a good explanation. One might argue that this is healthy because a naturalistic philosophy of science should reflect genuine disputes in scientific practice. But such dissonance among scientists may be exacerbated by philosophical commentaries, because philosophers of science typically rely on different evidence bases in an unsystematic way: some consult their intuitions, others first-hand experience as practitioners in the relevant scientific discipline, and yet others a small number of case studies of research articles. Although a narrow focus on a particular type of evidence can deepen our understanding of some aspects of scientific practice, if uncoordinated, it fails to provide a big picture of the scientific conceptual landscape (Weinberg and Crowley, 2009). Even worse, it may provide a distorted image of science.

Experimental philosophy (X-phi) of science is a relatively new approach that aims to overcome this problem. Specifically, it uses survey-experimental 
instruments to generate data about scientists' judgments on conceptual issues, in a hypotheses-oriented and controlled fashion, thereby complementing or confronting the kinds of evidence mentioned here regarding how scientists understand and use particular concepts (Griffiths and Stotz, 2008; Machery, 2016). Until very recently, experimental philosophy has not been much applied in the philosophy of science, despite its popularity in other fields of philosophy. ${ }^{1}$ $\mathrm{X}$-phi is even less popular in philosophy of economics, compared to other scientific fields (e.g., Stotz, 2009; Linquist et al., 2011; Knobe and Samuels, 2013). I think this is just a contingent fact, and there is no deep reason that prevents an experimental approach from being useful in the philosophy of economics. I argued elsewhere that this unfortunate situation should change (Nagatsu, 2013) and conducted one of the first consciously X-phi of economics studies (Nagatsu 2019 and Põder, 2018). Drawing on these results, I will argue that an X-phi approach can indeed bring conceptual clarity to some debates in philosophy of economics.

Another related field is worth a brief mention before discussing X-phi of economics. Philosophical questions concerning economics include not only methodological and conceptual ones about economics as a science, but also theoretical and normative ones within economics, such as the nature of justice, welfare, norms, and conventions. This field overlaps with philosophy both in content and in style, being highly theoretical, abstract, sometimes formal, and with little empirical input other than theorists' intuitions. The rise of experimental and behavioral economics, however, changed this situation, just like $\mathrm{X}$-phi has changed philosophy, and it has become increasingly popular to study these issues using experimental games of bargaining, coordination, and social dilemmas. I call this field experimental economics of philosophy to distinguish it from X-phi of economics, and to highlight the fact that its method comes from experimental economics, while the subject matter is of philosophical interest. Although it is in practice difficult to draw a distinct line between this and the rest of experimental economics, one can identify several studies with explicitly philosophical focus on, for example, justice (Konow, 2003), Humean and Lewisian conventions (Mehta, Starmer, and Sugden, 1994; Guala and Mittone, 2010; Guala, 2013), and moral judgments and behavior (Gold, Colman, and Pulford, 2014, 2015). Of particular interest for X-philes is the use of real monetary incentives, one of the delete "real" methodological features of experimental economics of philosophy that may be useful in other X-phi studies as well (Gold, Pulford, and Colman, 2013).

The chapter is organized as follows: first, I will introduce two working hypotheses concerning the variance and validity of scientific concepts, 
conceptual variance, and conceptual ecology hypotheses, which I borrow from running head $\mathrm{X}$-phi of biology and draw on throughout the chapter ("Conceptual variance and conceptual ecology"). Then, I introduce commonsensible realism as the received view in philosophy of economics ("Commonsensible realism"). In "Choice concepts: Folk vs. economic," I discuss folk vs. economic concepts of choice, f lower case draêmg on hetter study. In "Preference concepts: Behavioral, psychological, or constructive?" I discuss behavioral vs. mental interpretations of preferences that divide economists and psychologists. The penultimate section ("Tracking changing methodological practice: To nudge or not to nudge?") discusses how $\mathrm{X}$-phi can shed light on conceptual ecology in addition to conceptual variance. A brief conclusion follows ("Conclusion").

\section{Conceptual variance and conceptual ecology}

The early studies in X-phi of science (in particular Griffiths and Stotz, 2008) provide a useful framework for the empirical-conceptual investigation of economic science. This framework consists of two working hypotheses: conceptual variance and conceptual ecology. The conceptual variance hypothesis states that a given concept may have different meanings across different scientific communities; the conceptual ecology hypothesis states that there are often methodological reasons, both epistemic and practical, for such variance. More generally, scientists adapt cognitive resources, such as models, concepts, and other techniques to their own specific problem-solving domains to facilitate their cognitive and practical goals. This adaptation, or epistemic niche construction (Sterelny, 2010), gives rise to domain specificity (MacLeod,

2018 2016) of scientific practices. Conceptual variance can be understood as a manifestation of this domain specificity in scientific concepts, reflecting conceptual ecology.

In general, three types of conceptual variance can be distinguished: (i) folk vs. scientific variance, (ii) interdisciplinary variance, and (iii) intradisciplinary variance. The first concerns variance across lay and expert concepts, while the latter two concern variance across scientific communities, large and small, respectively. "Commonsensible realism" and "Choice concepts: Folk vs. economic" discuss (i); "Preference concepts: Behavioral, psychological, or constructive?" discusses (ii); and "Tracking changing methodological practice: To nudge or not to nudge?” discusses (iii). 


\section{Commonsensible realism}

Traditionally, philosophers of economics have discussed theoretical concepts in economics (mostly in the theory of consumer choice) in the context of realism. Uskali Mäki has been one of the proponents of commonsensible realism, according to which the entities and relationships of economic theory are part of the "common-sense furniture of the human world" (Mäki, 2002b, p. 95). In particular, the class of psychological states posited by the theory of consumer choice is part of "the ontic furniture of common-sense psychology, which we all employ in our daily lives regardless of whether we have an academic degree in psychology" (Mäki, 2000, p. 111). Daniel Hausman concurs: the unobservables in economics, that is, "beliefs, preferences, and the like are venerable. They have been a part of common sense understanding of the world for millennia ... there is no principled epistemological divide between the beliefs and desires [of] everyday life and the subjective probabilities and utilities of economics" (Hausman, 1998, pp. 197-99).

Although the motivations of Mäki and Hausman are different, they both dismiss the relevance of the observable/unobservable distinction to the philosophy of economics; unlike in the philosophy of physics, they insist, this distinction is unimportant for scientific realism debates in economics. Mäki wants to shift philosophers' attention away from ontological questions to more specific, methodological questions regarding the representational strategies of economists, such as isolation, abstraction, and idealization, and how to evaluate these strategies necessarily involving unrealistic assumptions. The key question concerns the truth, or "realisticness" of representations, not the existence of postulated entities. Although Hausman argues that scientific realism, including the kind of realism Mäki sees as central, is largely irrelevant to economic methodology, both agree that commonsensible realism provides necessary and sufficient ontology for economic theory.

Contrary to this received view, I argue that commonsensible realism is a necessary starting point of economic methodology, but it is not sufficient. First of all, there is a relevant analogy between realism in physics and economics; although unobservable entities like electrons do not figure in economics, the exact nature of latent constructs have always been controversial. For example, the nature of preferences has been extensively debated in the philosophy of economics (see "Preference concepts: Behavioral, psychological, or constructive?"). Preferences or utility are said to be latent not because they are too small to be seen with the naked eye but because they have to be inferred from observable behavior. Despite this difference, their nontransparent character gives rise to disagreement concerning 
the conceptual and ontological nature of preferences, just like esoteric concepts and entities in physics do. Commonsensible realism, on a strong reading, cannot explain why researchers disagree on the nature of preferences-we wouldn't expect such a disagreement if economic constructs are identical with concepts which everyone shares from everyday experience. Moreover, commonsensible realism lacks a resource to explain patterns of the disagreement-if there is any-about the nature of particular economic constructs. I show some evidence against the strong reading of commonsensible realism, and propose its weaker version as an alternative conceptual variance hypothesis in "Choice concepts: Folk vs. economic." Commonsensible realism needs to be qualified by accepting economic concepts' systematic departures from folk counterparts.

It is worth emphasizing at this stage that $\mathrm{X}$-phi of economics is distinguished from general surveys on the opinions of economists and other members of the general public. A well-known study demonstrated the systematic gap between folk and economists' opinions about the economy. This is a series of telephone surveys of 1,511 noneconomists and 250 economists conducted by the Washington Post/ Henry J. Kaiser Family Foundation/Harvard University Survey Project (Blendon et al., 1997). The main findings of this study include a systematic gap between economists' and lay people's reasoning about how the economy works. For example, lay people tend to see increased prices as a result of companies' price manipulation, while economists tend to see it as due to supply and demand. This and other findings reveal a systematic divergence between folk and economic theories of how the economy operates. But studies of this type cannot directly inform debates on commonsensible realism, because all the evidence shows is that lay people have their own folk-economic theory, which may be underscored by the common-sense concepts shared by the folk and economists. In order to investigate possible conceptual variance between folk and economists, a study needs to be designed to focus on concepts, not just opinions.

\section{Choice concepts: Folk vs. economic}

Ross (2011, p. 220) raises a thought-provoking challenge to commonsensible realism, speculating that those economists who are psychology or neuroscience skeptics "have a different concept of choice in mind" than that shared by noneconomists. This is surprising, because choice is not even latent or unobservable in the sense that preferences or beliefs are. Moreover, unlike these concepts that are formally defined in choice theory, the concept of choice itself is rarely explicitly characterized in the textbooks, as if people shared a common 
understanding of its meaning. ${ }^{2}$ But if Ross is right, that is, if these economists have a concept of choice different from the one held by noneconomists, commonsensible realism needs to be qualified. This has practical implications, too. Regarding the gap between the folk and economic theories of the economy mentioned above, for instance, the gap might be more difficult to bridge than initially thought if the two groups diverge even at the supposedly commonsensical conceptual level.

Specifically, Ross states that choice is a pattern of behavior that varies in response to incentives. We highlight two points: first, on this view, choice in economics is a population-scale phenomenon, rather than an individual psychological one. This implies that choice can have very heterogeneous causal bases if one zooms in to the individual scale, such as effortful decisionmaking, imitation, inertia, constrained random behavior, and so on. Second, since these causal bases are heterogeneous, the subject may or may not be conscious that she is making a choice. Consciousness is thus not a necessary (nor a sufficient) condition for behavior to count as choice in this economic sense. Nevertheless, choice has to vary in response to shifts in incentives in a theoretically tractable way.

Ross's conceptual variance hypotheses can be reformulated as follows:

- H1: Economists are more likely than noneconomists to think of a behavioral change as choice, if it is a response to incentive shifts.

- H2: Economists are more likely than noneconomists to think of a behavioral change as choice, even if the actor is not aware that she is responding to incentive shifts.

In order to test these hypotheses by eliciting the respondents' notions of choice, we constructed two sets of vignettes, that is, stylized descriptions of hypothetical scenarios in which the protagonist changes his or her behavior prompted by a range of events (Nagatsu and Põder, 2018). We tested the two hypotheses in two different sets of vignettes. In the first set, we manipulated the dimension concerning the cause of the protagonist's behavioral change (Linda's reduce meat consumption). We had four levels, namely, (i) belief change, (ii) price change, (iii) medical change, and (iv) "nudged" change. In the second set, we manipulated the dimension concerning the protagonist's awareness of the cause of their own behavioral change (John stops winking to his female colleagues), where the cause is fixed as an incentive change (frowns of disapproval by winkees). We had three levels, namely, (i) being aware of the cause, (ii) being unaware of it, and (iii) interrupted by a cause overdetermining behavior regardless of awareness. 
The order of the two sets were fixed, but the order of the vignettes within each set was randomized for different subjects.

We constructed two separate sets of vignettes (seven in total) instead of twelve by manipulating the two dimensions in $4 \times 3$ factorial design. ${ }^{3}$ The main reason for this choice is that some levels in the two dimensions are not independent and create implausible vignette cases. ${ }^{4}$ Thus we tested two dimensions, one at a time, in two separate sets of vignettes: the first set investigated the connection between the notion of choice and types of cause of behavioral change; the second set of vignettes investigated the connection between the notion of choice and what mediates behavioral change. At the end of each vignette, subjects were asked to agree or disagree to the statement: "Linda chose to eat less meat" and "John chose to stop winking," respectively, on a 7-point Likert scale.

We disseminated the online survey using Qualtrics (www.qualtrics.com). The link to the survey was disseminated using mailing lists at different universities in five countries: the United Kingdom (University of Reading), Finland (University of Helsinki, Hanken School of Economics), Estonia (Tallinn University of Technology), Italy (University of Milan), and Turkey (Bahcesehir University). The survey was also sent to the students who were enrolled in the course Understanding Economic Models (Fall semester 2016) at the Department of Political and Economic Studies, the University of Helsinki, before the course had started. Of the 185 respondents who started, 127 completed the survey (completion rate was 69 percent; mean time for completion was 8 minutes). We did not give incentives in money or course grade. The main part of the survey was followed by demographic questions, including the main area of study, the level of education (BA, MA, and $\mathrm{PhD}$ ), mother tongue, and gender, as well as a prompt to leave any comments on the survey in free form. The characteristics of the respondents are summarized in Table 7.1. We operationalized "economists" as those who selected "Economics" as the main area of study. "Business and Management" is distinguished from "Economics."

To summarize, we have two predictions:

- Prediction 1: other things being equal, economists (defined by their Main Area of Study) are more likely than noneconomists to agree to the statement "Linda chose to eat less meat" in the price change scenario but not in the others.

- Prediction 2: other things being equal, economists (defined by their Main Area of Study) are more likely than noneconomists to agree to the statement "John chose to stop winking" in the unconscious scenario but not in the others. 
Table 7.1 Respondents' characteristics

\begin{tabular}{|c|c|c|c|c|c|c|c|}
\hline \multicolumn{2}{|l|}{ Area of study } & \multicolumn{2}{|c|}{ Education } & \multicolumn{2}{|l|}{ Language } & \multicolumn{2}{|l|}{ Gender } \\
\hline Economics & 73 & $\mathrm{BA}$ & 34 & English & 16 & Male & 79 \\
\hline \multirow[t]{5}{*}{ Others } & 54 & MA & 25 & Estonian & 16 & Female & 48 \\
\hline & & $\mathrm{PhD}$ & 63 & Finnish & 34 & & \\
\hline & & $\mathrm{n} / \mathrm{a}$ & 5 & Italian & 23 & & \\
\hline & & & & Turkish & 17 & & \\
\hline & & & & Others & 21 & & \\
\hline Total & 127 & & 127 & & 127 & & 127 \\
\hline
\end{tabular}

Our regression analysis is largely consistent with our predictions and support Ross's hypotheses. In particular, answering "Economics" as the main area of study makes one more likely to judge Linda's incentive-induced behavioral change as a choice. This effect, call it the economist effect, is large (about 20 percent average marginal effects), statistically significant $(\mathrm{p}<0.05)$, and robust (the effect size remains the same regardless of the exact thresholds for responses to be categorized as positive or negative answer), confirming Prediction 1 . The results strongly suggest that economists are more likely than noneconomists to think of a behavioral change as choice if it is a response to incentive shifts. This supports Ross's hypothesis 1, as formulated above. The economist effect on judging John's unconscious incentive-induced behavioral change as choice is not as clear, and therefore we focus on the first economist effect here. ${ }^{5}$

Economists might have a distinctive, technical concept of choice that they apply in their scientific practice, but how do we know that the economist effect we observed reflect that methodologically relevant concept? The answer we advance is a specific version of commonsensible realism. Unlike the strong version, which identifies economic and folk concepts, this weak version accepts that economic concepts such as choice (and subjective beliefs, preferences, and the like) are continuous with common-sense counterparts but deviate from them in ways that reflect economic theoretical frameworks, such as the theory of choice. In other words, economists share some commonsense understanding of these concepts, which is overridden or partially modified by scientific disciplinary training (or alternatively purified by selfselective recruitment). While the strong version does not motivate empirical investigations of economic concepts (because we already know them from our 
everyday experience), the weak version motivates such investigations and also offers a plausible explanation of our observations that economists' concept of choice is affected by their theoretical frameworks.

The crucial questions are what constitutes the core "commonsensible" part of the choice concept, and what makes the economic concept of choice deviate from it. We hypothesized voluntariness as the core commonsensible of choice. Common sense tells economists (as well as noneconomists) that choice has to be voluntarily made-otherwise, you have no choice! In this sense, Linda's reduced meat consumption due to the increase in meat prices is less of a choice because of the limits imposed on a range of available options, thereby compromising the voluntary nature of her reduced meat consumption. According to the standard economic framework, however, choices simply reflect or "reveal" the subject's satisfaction of exogenous (i.e., given) preferences under certain constraints. In this framework, Linda's reduced meat consumption in response to price increase is a choice because her behavioral change still satisfies her preferences under a new, tighter budget constraint. This speculation provides a plausible mechanistic explanation of the economist effect we observed in the Linda vignette: while noneconomists interpreted the increase in prices as reducing the voluntary nature of Linda's response, economists did not, because their theory-laden concept of choice told them that it was irrelevant. Some might have explicitly thought: "Linda could have maintained the same level of meat consumption, by, for example, buying less clothes." To sum up, this study suggests that commonsensible realism in the strong sense needs to be abandoned, while its weaker version is a plausible cognitive hypothesis regarding how and why economists' concept deviates from their folk counterpart. In the next section, I turn to the preference concept, whose nature has been disputed between economics and psychology.

\section{Preference concepts: Behavioral, psychological, or constructive?}

The notions of preferences and utility are among the most contested ones in the history and philosophy of economics. Historians of economic thought have discussed the development of these notions from the nineteenth to the twentieth century before World War II (Moscati, 2013; Lewin, 1996; Hands, 2012). More recently, the rise of behavioral economics and neuroeconomics revived this debate. While the discussion of commonsensible realism in "Choice concepts: 
Folk vs. economic" concerns the variance between folk and scientific (economic) concepts, these debates on preferences explicitly concern variance of preference concepts in two scientific disciplines: economics and psychology. Roughly speaking, the debates take place in the context where psychology challenges economics for its lack of psychological realism. In this section, I will provide a brief overview of these debates and discuss how X-phi of economics can shed light on them.

The postwar development of revealed preference theory enabled economists to model choice behavior as utility maximization based on observable choice data and a set of parsimonious axioms regarding preference relations. Accordingly, the hedonic connotation of the utility concept-intensity of pleasures and pains-has been stripped away, and it has become simply a convenient way of indexing preferences that satisfy the axioms of revealed preference theory. There is a popular historical narrative among economists according to which this theoretical achievement is seen as a completion of the long-term separation of economics from psychological hedonism, under the influence of the contemporary behaviorism in the early twentieth century. Edwards (2016) calls it a "behaviorist myth"; however, this interpretation is misleading. First, strictly speaking, the notion of preferences never disappeared from choice theory, as originally envisioned by the young Paul Samuelson, the founder of revealed preference theory (Hands, 2010). Second, the core axioms of the theory (completeness and transitivity of preferences) are postulated a priori, not based on observations of human behavior using behaviorist methods such as conditioning. Third, Expected Utility Theory (Von Neumann and Morgenstern, 2004, first appeared in the second edition in 1947) — the standard theory of choice under risk and uncertainty-did not develop along the behaviorist line, either. This theory involves the notion of risk preference as a key construct, and Savage (1954) added an extra psychological construct of beliefs qua subjective probabilities. So, as a historical account, the behaviorist myth is just that, a myth. However, the myth may reflect an inherently ambivalent nature of the notion of preference in economics: on the one hand, the theory enables economists to infer (or reveal, as they say) preferences from observed choice data without data on mental or neurological processes. In this sense, the preference concept does not need psychology. On the other hand, the very axioms are based on a priori postulates about preference relations (and relations between subjective beliefs and preferences in the case of expected utility theory), which seem to be based on the introspective psychology of decision-making. Are preferences behavioral or psychological (mental)? 
As noted earlier, the debates over this question have been intensified by the rise of behavioral economics in the last quarter of the twentieth century and neuroeconomics in the beginning of the twenty-first century. Behavioral economics, mostly influenced by cognitive psychology, has demonstrated numerous empirical anomalies to expected utility theory and game theory; some neuroeconomists even go further and suggest that the very notion of preferences may have to be abandoned given the data from new neuroimaging techniques such as fMRI (Camerer, Loewenstein, and Prelec, 2005). In response to the increasing pressure to revise mainstream economic theories based on these new types of data, Gul and Pesendorfer (2008) argued that psychological and neurophysiological evidence is simply irrelevant to the economic theory of choice because the theory does not refer to mental states and therefore is "mindless." Gul and Pesendorfer (2008) initiated the neuroeconomics controversy among economists and methodologists. (For a very careful and thorough methodological analysis, see the target article Harrison, 2008, as well as the commentaries in the same issue). Just like the behaviorist myth, the controversy is a symptom of a deep disagreement between psychological (mental) and behavioral interpretations of preferences.

To focus on conceptual issues, I turn to philosophers of economics who try to explicitly define what preferences are. Hausman (2012) provides one of the clearest conceptual analyses of preferences, according to which preferences in economics are total subjective comparative evaluations. ${ }^{6}$ That is, they capture the agent's subjective rankings of available but competing alternatives after taking into account all relevant pro tanto reasons, which, jointly with her beliefs, cause (and justify and explain) her choice of one alternative over the other(s). So if Anne has two feasible evening plans, $b$ (going to a friend's barbecue party) and $c$ (going to the cinema), and prefers $c$ to $b$, and if her beliefs do not interrupt with this preference (e.g., by reminding her that the cinema is closed today), she will and should choose $c$ over b, because her preference $(c>b)$ has been in inequality formed by considering all the subjective factors that are relevant to her decisionmaking. Angner (2018) rejects Hausman's interpretation of preferences, based on the evidence that such mentalistic commitment on the part of economists cannot be found in (i) orthodox economics textbooks, (ii) commentaries by founding economists of the postwar neoclassical synthesis, or (iii) contemporary economists' practices. ${ }^{7}$

Angner's case against the mentalistic interpretation of the preference concept may seem to sway the balance between mental vs. behavioral interpretations toward the latter. In fact, however, Angner (2018) proposes the dissolution of the 
dichotomy by proposing a minimalist interpretation: preferences in economics are whatever the axioms of utility theory say they are. According to Angner, the preference concept is "implicitly defined" by virtue of its place in the axioms of choice theory and therefore has no intrinsic, definite meaning. This contextual view implies, first, that preference concept's definition can (implicitly) change as some axioms are modified; and second, even taking all the axioms as fixed, the empirical meaning of preferences may change depending on the domain to which the theory is applied by some correspondence rules.

Guala (2017) also denies the dichotomy between mental vs. behavioral interpretations of preferences and proposes a third interpretation, according to which preferences are dispositions with multiply realizable causal bases. ${ }^{8}$ This view is not behavioral because preferences may have mental causal bases. For example, a consumer's intransitive preference over three cars with three attributes may be caused by her use of a simple heuristic for pairwise comparisons: choose one that beats the other on most attributes. However, the view is not mentalistic, either, because preferences may have nonmental causal bases. For example, a three-member committee's intransitive preference over three candidates (a choice problem formally equivalent to the last example) is caused by institutional rules: majority voting through a sequence of pairwise comparisons of the candidates. In both cases, preferences are dispositions that explain choice that have multiply realizable causal bases, such as mental rules of thumb and institutional rules of aggregation.

Guala's example of the intransitive preferences of the consumer and the committee can be seen as an elaboration on the second implication of Angner's contextual account of preferences; that is, the meaning of preferences depends on the domain of application of choice theory. More generally, Guala identifies three conditions for preference-based choice theories to be explanatory of an agent's behavior: the agent in question is (1) consequence-driven, (2) motivated

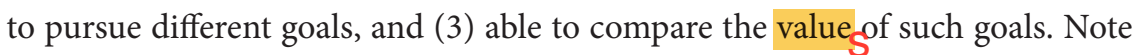
that these conditions themselves should not be given mentalistic interpretations. So predicates such as "is driven by," "is motivated to," and "is able to compare" are all applicable to nonhuman agents (neurons, bees, pigeons, etc.) and agents composed of human agents (committees, nation states, etc.), as well as to human agents with limited cognitive capacities (infants and boundedly rational people like us). In fact, conditions (2) and (3) come from the axioms concerning how preferences are ordered, for example, $b \geqslant c$ or $c \leqslant b$, and condition (1) comes from a particular correspondence rule used to infer preferences from observable behavior. We do not know a priori which agents' behavior fits the bill, and this 
seems to be the point at which philosophers have to hand the matter over to scientists.

Taken together, these two accounts of preferences in economics-Angner's Nagenlian contextual account and Guala's Fodorian multiple realizability account-offer a convincing argument to the effect that there is no definite answer to the question "are preferences mental (psychological) or behavioral?" There is nothing in the nature of preferences as such that can determine the answer, because it depends on how the axioms of choice theory implicitly define preference relations, and which domains the theory can be successfully applied to.

So if there is no philosophical disputes to be adjudicated here, what roles are left to X-philes of economics? I see at least two important roles of X-phi of economics here. First of all, the X-phi approach can show whether there is any systematic connection between the folk concept of preferences and its theoryladen, economic counterpart. Angner (2018, p. 21) suggests that everyday, connotations of theoretical constructs are simply irrelevant to scientific debates, citing Nagel's position that "such connotations are irrelevant . . . and are best ignored" (Nagel, 1961, pp. 91-92). However, this claim will have to be qualified if the weak version of commonsensible realism I proposed in "Choice concepts: Folk vs. economic" also applies to preferences. The folk concept of preferences is relevant to the understanding of economic counterpart if the latter's departures from the former are systematic. And in order to know if such a systematic connection exists, we need to empirically investigate what the commonsensible of preferences is, for which the X-phi approach will be necessary. Moreover, the commonsensible of preferences is relevant because preference-based choice theory is simultaneously used as a basis of normative welfare evaluations of agents when the theory is applied to individual human agents. In this specific but main domain of applications, then, economists are imposing their implicit definition of preferences on individuals. And it is not clear why the individuals' own conception of preferences are "best ignored" in this normative context.

Second, X-phi can be useful in investigating methodologically relevant interdisciplinary differences between economics and psychology, which may persist even after the dichotomy between behaviorism and mentalism has been dissolved. To see this, let us restrict the domain of application of choice theory to individual humans again.

In this domain (including consumer choice theory), the causal basis of preferences is most naturally interpreted as mental, as suggested by Guala's (2017) example of heuristic-based intransitive preferences, and also Angner's 
(2018) use of findings from cognitive science. Based on "far-reaching similarities" (Angner, 2018, p. 17) between how Hausman and cognitive scientists talk about preferences, Angner takes the findings of implicit biases (such as mere exposure effects) in cognitive science to be the evidence against Hausman's account of what preferences are in economics. This move is based on the assumption that what preferences are in this domain depends on what cognitive scientists say they are. But some economists disagree with even this localized mentalistic interpretation of preferences. Guala (2017) tries to dissolve this tension by suggesting that preferences are explanans for economists and explanandum for psychologists, that is, that economists explain individual choice based on preferences, which are in turn explained in terms of individual mental processes by psychologists. Ross (2014), however, questions such a neat division of explanatory labor. The economic concept of preferences, argues Ross, does not map onto individualscale mental processes, which are too heterogenous to provide a generalization about preferences; nevertheless, statistical analysis of a large number of pooled individual choice data can reveal projectible preferences at a market scale. Such projectability comes largely from the market structure in which individuals are embedded, that is, artificial environmental scaffolds such as informationprocessing technology and engineered (or emergent) institutional rules. Importantly, the market structure is not bounded by the limits of individual rationality. Rather, the market structure can be designed (or evolve) precisely to transcend the limitations of individual decision-making rationality. The revealed rational patterns, such as systematic responses to incentives, are thus an ecological property of the market, not of any single individuals.

Note that Ross's account of preferences-which is analogous to his account of choice discussed in "Choice concepts: Folk vs. economic"-is not strictly behavioristic because it leaves room for the psychology of latent individual mental processes to play a causal role in market phenomena. ${ }^{9}$ What he is resisting here is rather the prospect that psychology (or neuroscience for that matter) will eventually provide a general theory of what preferences are in economists' sense, supplanting the economic theory of choice.

If Ross (2011) is correct, in the domain of individual choice, economists are committed to the concept of preferences that are neither mental nor behavioral, but constructive: preferences emerge from the combination of individuals who process information internally and the market structures that scaffold their decisions and interactions. This hypothesis is testable by X-phi approach, and if supported by evidence, it may provide a novel explanation of the conservative nature of economic practices. For example, somewhat surprisingly, economics 
education remains more or less the same before and after the rise of behavioral economics, despite the prestige it has won over the last decades within the economics profession and its popularity outside academia. Core economic theories (e.g., price theory) have not been modified accordingly. ${ }^{10}$ Psychologists see this practice as unscientific, and economics students find it baffling.

Indeed, understanding this conservativeness of economics has been one of the leitmotifs in philosophy of economics: (How) can we methodologically justify economists' reliance on psychologically unrealistic models of choice? Traditionally, this question has been addressed in the general epistemological frameworks such as idealization or ideal types (Angner, 2015), and isolation of target systems by models (see Mäki, 2002a, part III) or the robustness of such unrealistic models. These general frameworks, however, cannot make sense of the methodological uniqueness of economics vis-à-vis psychology, for they do not explain why economic idealization is different from the kind of idealization psychologists engage in. ${ }^{11}$ In contrast, Ross's constructive characterization of preferences is based on his analysis of domain-specific methodology of economics, which general epistemological frameworks cannot penetrate. An $\mathrm{X}$-phi study designed to identify economists' concept of preferences and its deviations from the folk and psychological counterparts may demonstrate such a domain specificity of the preference concept, which will motivate more finegrained methodological discussions. For example, we can start from a surveyexperimental test of Hausman's 2012 account of preferences in economics as total subjective comparative evaluations, which Angner (2018) criticizes. Each dimension of Hausman's conceptual analysis can be operationalized and examined in a relatively straightforward way. A next step will be to test Ross's account of constructive preferences, which will require vignettes that draw directly on real economic modeling practices and a larger sample of economists. Such studies may demonstrate the domain specificity of economic methodology in a concrete manner, which can help other scientists and economists to better understand their methodological differences. We also expect the results to be relevant to economics pedagogy and the public understanding of economics as a science.

\section{Tracking changing methodological practice: To nudge or not to nudge?}

$\mathrm{X}$-phi is a useful approach to discovering systematic variances between folk and scientific concepts and between psychological and economic concepts. Given 
the diversity of economics, we should expect that conceptual variance exists even within economics. A literature survey by Cowen (2004), for example, identifies a few variations of the rationality concept in different fields of economics, such as consumer choice theory, macroeconomics, experimental economics, and game theory. In addition, two cases studies, one on Contemporary Revealed 2012 Preference Theory (Hands, 2011) and the other on behavioral economics (Guala, 2012 2011), suggest rather different understandings of preferences within economics. The conceptual ecology thesis justifies such a cohabitation of different concepts within science, whether across or within disciplines. However, some philosophers may think that X-phi is good at taking a static snapshot of conceptual landscape but incapable of analyzing dynamic methodological changes, should they arise in the same field. I have two responses, one generic and one specific.

First, it is uncontroversial that different empirical methods have different advantages and limitations, and complement each other. Somewhat simplifying, qualitative case studies, including historical analysis, detailed analysis of published articles, interviews, and participatory observations, are good at studying scientific practices in depth; in contrast, X-phi and bibliometrics (systematic analysis of published documents) are good at providing breadth, or an overview of conceptual landscape and trends and networks, respectively. Of course, X-phi is distinct from all other of these methods in being able to manipulate vignettes in a systematic, hypothesis-oriented way. But these methods are all needed to "the other" fully understand scientific concepts. To extend the contextual theory of scientific concepts a bit further, it is not difficult to see that concepts are implicitly defined not only by theoretical postulates and the rules of correspondence but also by the entire web of scientific practices, what Chang (2012) calls a system of practice. In our case of preferences in economics, the relevant practices include institutional engineering of market rules, welfare analysis of such policy interventions, and the normative individualism that underpins such welfare analysis. Qualitative methods are best suited for studying these practices in depth. ${ }^{12}$

Second, however, X-phi may provide methodologically relevant information about dynamic changes in economic methodology and elucidate the nature of accompanying disputes, if not dissolve them. In this section, I will use nudge paternalism as an illustrative case.

Nudges are defined as policy interventions in choice architecture-contexts in which individual choice takes place-that do not significantly change people's incentives or beliefs but still reliably produce welfare enhancing behavioral change (Thaler and Sunstein, 2008). Famous examples include the default change of pension choice (from opt-in to opt-out), and the automatic 
retirement savings mechanism (Save More Tommorrow ${ }^{\mathrm{TM}}$ ). These nudges are reverse engineered based on various psychological effects found by behavioral economists, such as loss aversion, framing effects, the status quo bias, and the present bias. There have been a great deal of debates around nudges among philosophers, economists, legal scholars, and policy makers, in particular regarding nudges' potential threats to individual liberty and autonomy and their ethical permissibility as a policy instrument. Economists are polarized in these debates, some embracing nudges and others rejecting them altogether. But it is not clear why and on what grounds they disagree. In particular, is the skepticism based on some moral conviction about individual autonomy and freedom or more subtle methodological (epistemic and practical) reasons? The conceptual ecology thesis and X-phi can illuminate the nature of this debate from a methodological perspective.

First, consider Ross's conceptual ecology thesis. Ross (2011) justifies his hypothesized variance between the economic, constructive concept of preferences and its psychological, individualistic counterpart, discussed in "Preference concepts: Behavioral, psychological, or constructive?" in terms of the practical concerns of respective fields as follows: psychologists are interested in the process of individual valuation and motivation because that is the scale on which most psychological interventions take effect, whereas economists are interested in the population-scale responses to incentive changes because that is the scale on which most economic interventions such as subsidies and taxes operate. At a very general level, this seems to be a plausible and useful characterization of the different epistemic and practical concerns of the two disciplines. And this conceptual ecological thesis provides a methodological insight into the debates around nudges.

Notice that Ross's (2011) own definition of preference and choice excludes nudged behavioral change from economic choice because by definition nudges are not incentives. However, there are significant conceptual similarities between incentives and nudges. First, both aim at population-scale behavioral change by indirectly intervening on the environment-constraints and choice architecture, respectively-rather than by directly intervening on individuals' motivations or cognition. Second, both are quiet about the exact psychological processes underlying behavioral change. Incentives presuppose that choices will respond to them, but there is tentative evidence that economists do not consider this process to be necessarily conscious, as discussed in "Choice concepts: Folk vs. economic" (see footnote 5). One might think that nudges are different because behavioral economists study nonstandard preferences caused by psychological 
biases, but note that many of the psychological effects I have listed here are experimental effects rather than causal mechanisms (see Guala, 2017, p. 9). Although several plausible psychological mechanisms have been proposed and tested in the lab as explanations of these effects, nudges are proposed based on their reliable effects at a population scale, rather than on the exact mechanisms that generate them. Third, both incentives and nudges presuppose exogenous preferences, though in crucially different ways. Incentives affect budget constraints, taking for granted people's preferences as given. Similarly, nudges change choice architecture, taking for granted people's preferences that nudges allegedly help manifest by removing psychological biases.

Given these similarities, it is no surprise that some pragmatic economists (e.g., Chetty, 2015) embrace nudges as part of economists' toolbox on par with incentives in behavioral public policy. In fact, there is not much in Ross's ecological thesis that prevents economists' adoption of nudges, given the latter's characteristics as (i) population-scale, (ii) mechanism-neutral, (iii) preferencereserving interventions. What do economists think? An X-phi study can examine whether and why economists (and others) accept nudges as legitimate policy interventions by systematically manipulating these factors.

In the X-phi study discussed in "Choice concepts: Folk vs. economic," we found evidence that economists' intuition about nudged behavioral change is not different from that of noneconomists. Nagatsu and Põder (2018) asked participants whether Linda's reduced meat consumption, nudged by the new arrangement of cafeteria food displays (another classic example of nudges in Thaler and Sunstein [2008]), was a choice. The mean answer was least positive among the four scenarios (4.51 on 1 "Strongly disagree" to 7 "Strongly agree") and not significantly different from noneconomists' responses $(4.07, \mathrm{p}$ (T-test) $=0.12$, $\mathrm{p}$ (Wilcoxon Rank Sum test $)=0.23$ ). This case, however, is not informative because the scenario was explicitly holding Linda's preference for meat as fixed. A better scenario should incorporate (iii) by making it explicit that Linda has a preference to reduce meat, which a nudge helps to satisfy. This way, X-phi can investigate not only whether economists accept nudges but also why.

So far, philosophers of economics have discussed nudges as ethical problems based on their understanding of what preferences are (Hausman and Welch, 2010; Bovens, 2009). Incidentally, both Hausman and Bovens subscribe to the concept of preferences as subjective total evaluations of alternatives, which Angner (2018) rejects as irrelevant to economics. I do not necessarily think that such ethical critiques are irrelevant because (a weak version of) commonsensible realism provides a link between folk and economic concepts of 
preferences in the domain of individual choice. But if economists see nudges as a population-scale intervention tool, ethical critics will have to justify why their ethical standards, based on a philosophical model of practical reasoning, have to weigh in economics. Also, philosophers focusing on mechanisms of nudges (Heilmann, 2014; Nagatsu, 2015; Grüne-Yanoff, 2016) will have to justify why mechanisms are important and in what level of details, if economists themselves (even behavioral economists) do not find issues of psychological mechanisms central for their methodology. We might be barking up the wrong trees.

Note that I am not arguing that philosophers of economics should refrain from participating in controversial contemporary debates in economics. On the contrary, I think that philosophers' participation can serve many functions such as providing conceptual clarification and outsiders' criticism. At the same time, there is a real danger that we philosophers will obscure the real issue by smuggling in our own perspectives to the debates, such as practical reasoning and mechanistic philosophy of science, in this case. The X-phi approach works as an antidote because it (i) reminds us of the domain specificity of economics (conceptual ecology), (ii) forces us to formulate hypotheses regarding the construction of economic concepts and how they are related to folk and other scientific concepts (conceptual variance), and (iii) gives us a way to test these hypotheses, in combination with evidence from other qualitative and nonexperimental studies of economics practices.

\section{Conclusion}

In this chapter, I have outlined what experimental philosophy of economics is and what it can do. It is an survey-experimental approach to illuminate $\mathrm{S}^{\mathrm{con}} \mathrm{ceptual}$ issues in economics, driven by the conceptual variance and conceptual ecology as the working hypotheses. I have introduced our own study that suggests that economists think of choice in a systematically different way than noneconomists, specifically as a response to incentive shifts. I have suggested that this result can be best understood as a manifestation of the weak version of commonsensible realism; that is, the economic concept of choice is linked to the common-sense counterpart but departs from it in a systematic way. I have also discussed the concept of preferences that are contested between economists and psychologists, introducing their behavioral, mental, and constructive interpretations in the literature. I suggested that these interpretations are testable and may provide a novel understanding of economic methodology revealing its domain 
AQ: Please check OK whether the edit in this sentence is appropriate.

specificity. Finally, I have discussed the recent nudge debates as a case in which economists themselves disagree on the proper methodology of economics. Building on Ross's conceptual ecology thesis, I have highlighted three similar aspects of incentives (the standard tool of economic intervention) and nudges (a new and controversial tool), namely, their population-scale, mechanismneutral, preference-reserving characters. We can analyze disagreements among economists at a deeper conceptual level by eliciting economists' responses by systematically varying vignettes along these three dimensions. At this stage, these ideas are more like thought experiments, with the exception of the real study of choice that we have conducted. And even that study has not covered a large enough, representative sample of economists. To do so will require more forces, so I welcome readers to join me in the exploration of this promising conceptual terra incognita.

\section{Notes}

1 In PhilPapers experimental philosophy of science does not have its own category; instead related papers are scattered across categories such as Foundations of Experimental Philosophy, Misc. and Experimental Philosophy, Misc. See https://ph ilpapers.org/browse/experimental-philosophy. The situation is similar on popular blogs and edited volumes on X-phi.

2 In economics, choice and behavior are often used interchangeably, or the term choice behavior is used.

3 Griffiths, Machery, and Linquist, (2009) for example, used $2 \times 2 \mathrm{~b} \times 2=8$ vignettes. More generally, in social research it is common to use more dimensions with more levels, resulting in a vast number of vignettes. Such design typically requires more subjects and random assignment of these subjects into different subsets of vignettes because it is practically impossible to expose each individual to more than a certain number of vignettes due to fatigue effects. Factorial surveys with this design are often not driven by clear hypotheses, unlike our case (see Nock and Guterbock, 2010, for a review).

4 See Auspurg and Hinz (2014, pp. 40-42) for the problems of implausible and illogical vignettes and ways to address them. In our case, (i) belief change and (iii) nudged change are respectively associated with conscious and unconscious mental processing: the agent is usually conscious about her behavioral change when she does so because of a changed belief; in contrast, if one changes behavior because of a nudge, often the change is not transparent to the agent. Discussions on the ethical permissibility of nudge-based behavioral policies revolve around this worry; see Thaler and Sunstein (2008). 
5 The effect is large (about 18 percent average marginal effects) and significant $(\mathrm{p}<0.05)$ but not robust, since the effect disappears in a model that is more permissive in categorizing responses as positive (this model takes 5,6 , and 7 on the 7-Likert scale as the positive answer). We can say that the economist effect exists only under the assumption that it should be detected in terms of a stronger agreement to the statement. Also, models that take levels of education as categorical rather than linear do not show the economist effect. Thus the second hypothesisthat economists are more likely than noneconomists to think of a behavioral change as choice even if the actor is not aware that she is responding to incentive shifts-is supported only under restrictive model assumptions.

6 Although Hausman does not cite it, Bovens (1992) offered a similar definition of preferences 20 years before in discussing the rationality of practical reasoning. Hausman's original contribution is to apply this definition of preferences to economics.

7 Angner also refers to empirical findings from cognitive science that show that people actually do not form preferences by integrating partial evaluations, and evolutionary explanations of why this has been adaptive.

8 See also (Ross, 2011). As one can imagine from our discussion in 4, Ross has a very similar definition of preferences in economics.

9 Ross (2014, p. 416) is, however, critical about the empirical success and theoretical importance of the most famous model of boundely rational choice, Cumulative Prospect Theory (Tversky and Kahneman, 1992). I cannot discuss this substantial scientific debate here.

10 Some textbooks now have a chapter on behavioral economics, but it is treated more like an added topic, rather than a foundation of a complete revision of price theory.

11 Kahneman (2011) clearly indicates that psychological models such as the dualsystem models are idealization.

12 See Wagenknecht, Nersessian, and Andersen (2015) for a general discussion of qualitative approach in philosophy of science. MacLeod and Nagatsu $(2016,2018)$ demonstrate the value of such methods in studying conditions for successful interdisciplinary model-building involving economists and ecologists.

\section{References}

Angner, E. (2015). To navigate safely in the vast sea of empirical facts. Synthese, 192(11): $3557-75$.

Angner, E. (2018). What preferences really are. Philosophy of Science, 85: 660-81.

Auspurg, K. and Hinz, T. (2014). Factorial Survey Experiments. Los Angeles: Sage Publications. 
Blendon, R. J., Benson, J. M., Brodie, M., Morin, R., Altman, D. E., Gitterman, D., Brossard, M., and James, M. (1997). Bridging the gap between the public's and economists' views of the economy. The Journal of Economic Perspectives, 11(3): 105-18.

Bovens, L. (1992). Sour grapes and character planning. The Journal of Philosophy, 89(2): 57-78.

Bovens, L. (2009). The ethics of nudge. In T. Grüne-Yanoff and S. O. Hansson (Eds.), Preference Change: Approaches from Philosophy, Economics and Psychology (Chapter 10, pp. 207-19). Berlin and New York: Springer.

Camerer, C., Loewenstein, G., and Prelec, D. (2005). Neuroeconomics: How neuroscience can inform economics. Journal of Economic Literature, 43(1): 9-64.

Chang, H. (2012). Is Water H2O? Evidence, Pluralism and Realism. Boston Studies in the Philosophy of Science. Springer: Dordrecht.

Chetty, R. (2015). Behavioral economics and public policy: A pragmatic perspective. American Economic Review, 105(5): 1-33.

Cowen, T. (2004). How do economists think about rationality? In M. Byron (Ed.), Satisficing and Maximizing: Moral Theorists on Practical Reason (Chapter 11, pp. 213-36). Cambridge: Cambridge University Press.

Edwards, J. (2016). Behaviorism and control in the history of economics and psychology. History of Political Economy, 48(suppl 1): 170-97.

Gold, N., Colman, A. M., and Pulford, B. D. (2014). Cultural differences in responses to real-life and hypothetical trolley problems. Judgment and Decision Making, 9(1): 65 .

Gold, N., Pulford, B. D., and Colman, A. M. (2013). Your money or your life: Comparing judgements in trolley problems involving economic and emotional harms, injury and death. Economics and Philosophy, 29(2): 213-33.

Gold, N., Pulford, B. D., and Colman, A. M. (2015). Do as I say, don’t do as I do: Differences in moral judgments do not translate into differences in decisions in real-life trolley problems. Journal of Economic Psychology, 47(Supplement C): $50-61$.

Griffiths, P. E., Machery, E., and Linquist, S. (2009). The vernacular concept of innateness. Mind and Language, 24(5): 605-30.

Griffiths, P. E. and Stotz, K. (2008). Experimental philosophy of science. Philosophy Compass, 3(3): 507-21.

Grüne-Yanoff, T. (2016). Why behavioural policy needs mechanistic evidence. Economics and Philosophy, 32(3): 463-83.

AQ: Please provide publisher Guala, F. (2011). Are preferences for real? Choice theory, folk psychology, and the location and page range. hard case for commonsensible realism. In J. Kuorikoski, A. Lehtinen, and P. Ylikoski (Eds.), Economics for Real: Uskali Mäki and the Place of Truth in Economic. Routledge.

Guala, F. (2013). The normativity of Lewis conventions. Synthese, 190(15): 3107-22. 
Guala, F. (2017). Preferences: Neither behavioural nor mental. DEMM Working Paper, Number 5.

Guala, F. and Mittone, L. (2010). How history and convention create norms: An experimental study. Journal of Economic Psychology, 31(4): 749-56.

Gul, F. and Pesendorfer, W. (2008). The case for mindless economics. In A. Caplin and A. Schotter, (Eds.), The Foundations of Positive and Normative Economics: A Handbook (chapter 1, pp. 3-42). Oxford: Oxford University Press.

Hands, D. W. (2010). Economics, psychology and the history of consumer choice theory. Cambridge Journal of Economics, 34(4): 633-48.

Hands, W. (2011). Realism, commonsensibles, and economics: The case of contemporary revealed preference theory. In P. Ylikoski, A. Lehtinen, and J. Kuorikoski (Eds.), Economics for Real: Uskali Mäki and the Place of Truth in

AQ: Please provide page range. remove

AQ: Please provide page range.

Hands, W. (2012). Realism, commonsensibles, and economics: The case of contemporary revealed preference theory. In P. Ylikoski, A. Lehtinen, and J. Kuorikoski (Eds.), Economics for Real: Uskali Mäki and the Place of Truth in Economic. Routledge.

Harrison, G. W. (2008). Neuroeconomics: A critical reconsideration. Economics and Philosophy, 24: 303-44.

Hausman, D. M. (1998). Problems with realism in economics. Economics and Philosophy, 14: 185-213.

Hausman, D. M. (2012). Preference, Value, Choice, and Welfare. Cambridge: Cambridge University Press.

Hausman, D. M. and Welch, B. (2010). Debate: To nudge or not to nudge. The Journal of Political Philosophy, 18(1): 123-36.

Heilmann, C. (2014). Success conditions for nudges: A methodological critique of libertarian paternalism. European Journal for Philosophy of Science, 4: 75-94.

Kahneman, D. (2011). Thinking, Fast and Slow. Macmillan.

Knobe, J. and Samuels, R. (2013). Thinking like a scientist: Innateness as a case stuay.

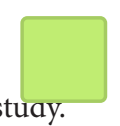
AQ: Please provide publisher location. Cognition, 126(1): 72-86.

Konow, J. (2003). Which is the fairest one of all? A positive analysis of justice theories. Journal of Economic Literature, 41(4): 1188-1239.

Lewin, S. B. (1996). Economics and psychology: Lessons for our own day from the early twentieth century. Journal of Economic Literature, 34(3): 1293-323.

Linquist, S., Machery, E., Griffiths, P. E., and Stotz, K. (2011). Exploring the folkbiological concept of human nature. Philosophical Transactions of the Royal Society: B Biological Sciences, 366: 444-53.

Machery, E. (2016). Experimental philosophy of science. In W. Buckwalter and J. Sytsma (Eds.), A Companion to Experimental Philosophy (chapter 33, pp. 475Wiley.

2018MacLeod, M. (2016). What makes interdisciplinarity difficult? Some consequences of domain specificity in interdisciplinary practice. Synthese.

AQ: Please provide publisher location

AQ: Please provide volume number and page range. 
MacLeod, M. and Nagatsu, M. (2016). Model coupling in resource economics: Conditions for effective interdisciplinary collaboration. Philosophy of Science, 83: 412-33.

MacLeod, M. and Nagatsu, M. (2018). What does interdisciplinarity look like in practice: Mapping interdisciplinarity and its limits in the environmental sciences. Studies in History and Philosophy of Science Part A, 67: 74-84.

Mäki, U. (2000). Reclaiming relevant realism. Journal of Economic Methodology, 7(1): $109-25$.

Mäki, U. (2002a). Fact and Fiction in Economics: Models, Realism and Social Construction. Cambridge: Cambridge University Press.

Mäki, U. (2002b). Some nonreasons for nonrealism about economics. In U. Mäki (Ed.), Fact and Fiction in Economics: Models, Realism and Social Construction (Chapter 4, pp. 90-104). Cambridge: Cambridge University Press.

Mehta, J., Starmer, C., and Sugden, R. (1994). Focal points in pure coordination games: An experimental investigation. Theory and Decision, 36(2): 163-85.

Moscati, I. (2013). Were Jevons, Menger, and Walras really cardinalists? on the notion of measurement in utility theory, psychology, mathematics and other disciplines, ca. 1870-1910. History of Political Economy, 45(3): 373-414.

Nagatsu, M. (2013). Experimental philosophy of economics. Economics and Philosophy, 29(2): 263-76.

Nagatsu, M. (2015). Social nudges: Their mechanisms and justification. Review of

AQ: Please provide complete details if available. Philosophy and Psychology, 6: 481-94.

Nagatsu, M. and Põder, K. (2018). What is the economic concept of choice? An experimental philosophy study. under review.

Nagel, Ernest (1961). The Structure of Science: Problems in the Logic of Scientific Explanation. London: Routledge \& Kegan Paul.

Nock, S. L. and Guterbock, T. M. (2010). Survey experiments. In P. V. Marsden and J. D. Wright (Eds.), Handbook of Survey Research (Chapter 28, 2nd ed., pp. 837-64). Bingley: Emerald Publishing Group Limited.

Ross, D. (2011). Estranged parents and a schizophrenic child: Choice in economics, psychology and neuroeconomics. Journal of Economic Methodology, 18: 217-31. Ross, D. (2014). Philosophy of Economics. New York: Palgrave Macmillan. Savage, L. J. (1954). The Foundations of Statistics. New York: Wiley.

Sterelny, K. (2010). Minds: Extended or scaffolded? Phenomenology and the Cognitive Sciences, 9(4): 465-81.

Stotz, K. (2009). Philosophy in the trenches: From naturalized to experimental philosophy (of science) introduction. Studies In History and Philosophy of Science, 40: $225-26$.

Thaler, R. H. and Sunstein, C. R. (2008). Nudge: Improving Decisions about Health, Wealth, and Happiness. New Haven: Yale University Press.

Tversky, A. and Kahneman, D. (1992). Advances in prospect theory: Cumulative representation of utility. Journal of Risk and Uncertainty, 5: 297-323. 
Von Neumann, J. and Morgenstern, O. (2004). Theory of Games and Economic Behavior (60th anniversary edition). Princeton: Princeton University Press.

Wagenknecht, S., Nersessian, N. J., and Andersen, H. (Eds.) (2015). Empirical Philosophy of Science: Introducing Qualitative Methods into Philosophy of Science. New York: Springer.

Weinberg, J. M. and Crowley, S. (2009). The X-phi(les): Unusual insights into the nature of inquiry. Studies In History and Philosophy of Science, 40: 227-32. 